\title{
Multidisciplinary Management of Metastatic Hemangiopericytoma Presenting with Hypoglycemia
}

\author{
Hendrick L', Angel W' ${ }^{2}$, Besh $\mathrm{S}^{3}$, O’Brien T ${ }^{4}$, Goins \\ $\mathbf{N}^{1}$ and Dickson $\mathbf{P}^{1 *}$ \\ ${ }^{1}$ Department of Surgery, Division of Surgical Oncology, \\ University of Tennessee Health Science Center, USA \\ ${ }^{2}$ Memphis Radiological P.C, USA \\ ${ }^{3}$ Division of Hematology/Oncology, University of \\ Tennessee Health Science Center and West Cancer \\ Center, USA 4Memphis Pathology Group, USA \\ *Corresponding author: Dickson PV, Department \\ of Surgery, Division of Surgical Oncology, University of \\ Tennessee Health Science Center, 910 Madison, Ave. $3^{\text {rd }}$ \\ Floor, Memphis, TN 38163, USA
}

Received: January 26, 2017; Accepted: February 28, 2017; Published: March 10, 2017

\begin{abstract}
Hemangiopericytomas (HPCs) are rare soft tissue tumors that arise from pericytes surrounding capillaries and venules and can occur throughout the body. We report the case of a 66-year old male with a history of a resected brain tumor that had been originally diagnosed as atypical meningioma. Two years later he presented with refractory hypoglycemia and was found to have multifocal liver metastases with biopsy revealing HPC. Evaluation of his hypoglycemia reveal suppressed insulin, C-peptide, and IGF-I levels and a normal IGF-II level. Biopsy of one of the liver masses revealed morphologic features consistent with HPC and re-review of his brain tumor pathology showed the same histomorphology. His liver metastases were treated with a combination of surgical resection and serial chemoembolization resulting in correction of his hypoglycemia. He has undergone continued serial treatments with chemoembolization with stabilization of his disease. Hepatic metastases from HPC are rare. Hypoglycemia in patients with HPC is likely driven by tumor production of pro-IGF-II peptide, a precursor of IGF-II. Given the paraneoplastic symptoms in these patients, cytoreduction is warranted. A well-coordinated multidisciplinary treatment plan and review of potential therapies is important in treating these unique patients.
\end{abstract}

Keywords: Hemangiopericytoma; Hypoglycemia; Liver metastases

\section{Abbreviations}

WHO: World Health Organization; MRI: Magnetic Resonance Imaging; IGF: Insulin like Growth Factor; HPC: Hemangiopericytoma; CT: Computed Tomography; NICTH: Non-insulin-Cell Tumor Hypoglycemia

\section{Case Presentation}

A 66-year-old man was initially referred to our institution for progressive left sided weakness and imaging demonstrating a brain mass. His history included pre-referral resection of a brain tumor 5 years prior. Outside surgical and pathology reports were obtained and documented subtotal resection of a large right parafalcine meningioma, WHO grade I, which was hypercellular with Ki-67 index of $18 \%$ without histologic features of atypia. MRI at our hospital demonstrated a $3.6 \times 4.2 \times 2.9 \mathrm{~cm}$ recurrent tumor with associated compression of adjacent brain parenchyma and mild peritumoral edema. He underwent redo craniotomy with microsurgical resection of the recurrent tumor. Pathology was reported as an atypical meningioma, WHO grade II. He subsequently was treated with postoperative partial brain radiotherapy to a total dose of 54 Gy in 30 fractions.

Two years later he was brought to the emergency department after being found unconscious at home. On evaluation his blood glucose was $30 \mathrm{mg} / \mathrm{dl}$, which initially responded to administration of $1 / 2$ ampoule D50. However, shortly thereafter his blood glucose dropped back to $43 \mathrm{mg} / \mathrm{d}$ land he was started on a D10 infusion. On physical exam he became appropriately oriented, had mild but reportedly stable left sided weakness and his abdomen was soft but distended with a large palpable mass in the epigastrium. Evaluation for hypoglycemia revealed a suppressed insulin level of 1.1 milliunit/L (4.2-27.9) and C-peptide of $0.61 \mathrm{ng} / \mathrm{ml}(0.80-3.80)$, HbAlC $4.1 \%$ (4.06.0), IGF-I $36 \mathrm{ng} / \mathrm{ml}$ (43-195), IGF-II $346 \mathrm{ng} / \mathrm{ml}$ (267-616), negative sulfonylurea screen, and normal random cortisol level. The IGF-II to IGF-I ratio was calculated at 9.6:1. Brain imaging demonstrated no evidence of locally recurrent tumor, however, abdominal CT and MRI revealed multiple bilobar hepatic masses (Figure 1A). There were no extra hepatic masses identified. Subsequent biopsy of one of the hepatic lesions revealed a neoplasm composed of monotonous cells with interspersed "staghorn" vessels highlighted by CD31 and CD34 immunoperoxidase stains, morphologically consistent with a diagnosis of hemangiopericytoma. Re-review of the brain tumor resection slides demonstrated similar morphologic findings (Figure 2A).

Given the patient's refractory hypoglycemia and the extent and distribution of his liver metastases, his case was discussed in a multidisciplinary setting and a liver directed treatment approach was designed. He underwent operation to resect a large pedunculated lesion from segment 3 (Figure 1B) that was causing significant displacement of surrounding viscera. Pathology revealed a $13 \mathrm{~cm}$ mass with features consistent with hemangiopericytoma (Figure 2B). Three days later he underwent a staged chemoembolization using hydrogel microspheres loaded with doxorubicin to treat the large tumor within the right lobe of the liver. The procedure was staged to minimize the risk of tumor lysis syndrome given the large tumor volume. Over the course of the next several months, serial embolizations using both drug eluting particles and bland acrylic polymer microspheres were performed. 

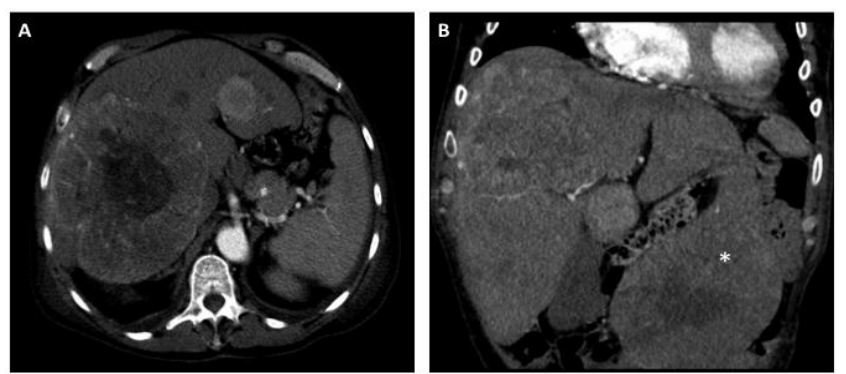

Figure 1: Axial CT image revealing a large metastasis occupying much of the right hemi-liver $(A)$ and coronal image demonstrating a large exophytic metastasis emanating from segment 3 (B).
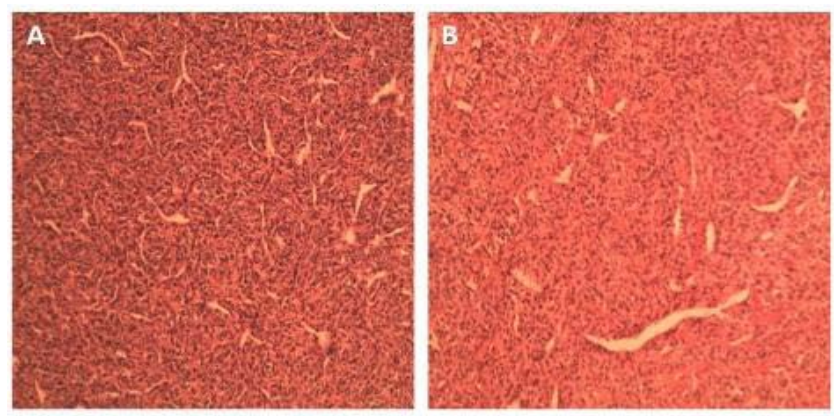

Figure 2: Photomicrograph of H\&E stains (100X) of resected liver mass (A) and brain mass $(B)$ demonstrating staghorn vasculature with spindle cells typically observed in HPC.

At last follow up he was 13 months out from initiation of treatment of his hepatic metastases with multiphasic CT demonstrating central necrosis of the larger tumors with minimal residual disease in the periphery of the lesions (Figures 3), no episodes of hypoglycemia, and a performance status improved to the point he has returned to work part time.

\section{Discussion}

Hemangiopericytomas (HPC) were first described by Stout and Murray in 1942 [1] and are rare tumors that arise from pericytes, the contractile cells surrounding capillaries and venules [1,2]. These tumors are most commonly diagnosed in the fifth decade of life without a clear gender distribution [2,3]. They are indiscriminate in their primary site of origin with the majority of reported cases in the lower extremities, axilla, pelvis, retroperitoneum, and head and neck $[2,4]$. These tumors may also arise within the central nervous system where they are often closely related to the meninges [5]. Overall 5-year survival rates for localized disease treated with complete resection of the primary tumor are reported to be between $71 \%$ and $86 \%$ [6-8] with 5 -year recurrence rates of up to $65 \%$ for tumors arising from the meninges [9]. The most common sites of metastatic disease are bone, liver, and lung [10]. Complete surgical resection is the mainstay of treatment for HPC.

Multimodal imaging allows for optimal visualization and more accurate diagnosis of these lesions and is particularly useful when evaluating metastatic disease. Ultrasound reveals a hypoechoic lesion, which becomes hyperechoic during the arterial phase of contrast administration due to the marked vascularity of HPC. On contrast

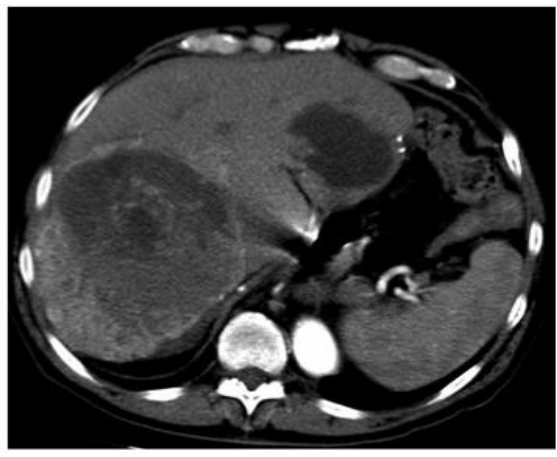

Figure 3: Recent surveillance imaging demonstrating reduction in size and internal necrosis of large right hepatic metastasis and a peripheral left liver metastasis.

enhanced CT scan the lesions are expected to have well defined borders and be more prominent during the arterial phase. MRI reveals a well-defined lobular lesion with enhancement after administration of gadolinium contrast. These characteristic imaging findings are consistent for both primary and metastatic lesions $[11,12]$.

Histopathologic analysis of HPC reveals staghorn vasculature with spindle cells (Figure $2 \mathrm{~B}$ ), which alone is often insufficient to distinguish meningeal HPC from anaplastic meningioma [13]. For this reason immunohistochemistry has an important role in the diagnosis of these lesions. STAT-6 has been reported to be present in $95-100 \%$ of both meningeal solitary fibrous tumors as well as meningeal HPC, and appears to be the most reliable marker for HPC $[14,15]$ with a reported sensitivity of $96 \%$ and a specificity of $100 \%$ in one recent study [16]. A combination of CD-34 and ALDH-1 has also been shown to be both sensitive and specific for differentiation of HPT from meningioma [16].

The most common sites of metastatic disease in patients with intracranial HPT are bone, liver, and lung. Recent case series report rates of recurrence with extracranial metastatic disease after primary resection to be between $13 \%$ and $31 \%[6,17,18]$. Although uncommon, others have described hypoglycemia in association with metastatic HPC [19]. Non-islet-cell tumor hypoglycemia (NICTH) is driven by tumor secretion of the precursor of IGF-II, pro-IGFII peptide or "big IGF." Liver synthesized IGF-II is typically bound to serum IGF-binding proteins (IGFBPs) forming biologically inactive complexes. Tumor synthesized IGF-II, however, binds to IGFBPs and forms biologically active binary complexes. Pro-IGF-II also suppresses growth hormone and causes decreased synthesis of IGFBPs. This permits increased levels of unbound and active IGF-II. When these active complexes or unbound IGF-II bind to insulin and IGF receptors in the liver and peripheral tissues there is decreased release of glucose into circulation and increased peripheral glucose metabolism resulting in hypoglycemia. Although plasma IGF-II levels were within normal range, the ratio of IGF-II to IGF-I was elevated at 9.6:1, consistent with NICTH [20]. Given the humorally mediated symptoms related to these metastases, an aggressive approach for cytoreduction is warranted. It is important to also consider medical therapies that may help raise blood glucose levels such as glucocorticoids, glucagon, or recombinant human growth hormone [21]. 
As hepatic metastases are extremely rare sequelae of this disease there is no defined consensus regarding their management. For resectable lesions excision is the preferred strategy [22]. The utility of hepatectomy, however, is dependent on the extent and geography of metastases as well as the patient's performance status and adequacy of the anticipated future liver remnant. In our patient we chose to resect the large lesion protruding from the left lateral liver (Figure 3 ) as it was causing significant local symptoms in addition to a likely contribution to his hypoglycemia. The number and location of the rest of the liver lesions as well as his medical fitness at the time prohibited further aggressive surgical debulking. Notably, however, the patient was able to come off of the D10 infusion 2 days post-operatively.

For patients with diffuse hepatic metastases other liver directed therapies have been reported to be effective. Both ablative and hepatic arterial directed therapies have been utilized in patients with HPC. A Japanese report describes a successful management of a patient presenting with multifocal hepatic metastases 8 years after resection of the primary tumor. Following combination treatment with radiofrequency ablation and transcatheter arterial chemoembolization the patient achieved a 5-year progression free survival [23]. Given the distribution of hepatic lesions in our patient we elected to perform resection of a large exophytic lesion from the left lateral liver which was causing local compressive symptoms followed by serial embolization procedures to treat additional diffuse hepatic disease.

There are two reports in the literature of liver transplantation for patients with metastatic HPC. One patient underwent liver transplantation due to refractory hypoglycemia associated with his metastatic disease and achieved a 4 year disease free survival [24]. A second patient who underwent living donor transplantation achieved a 2 year disease free survival and overall survival of 5 years [25].

Systemic therapy options for HPC are limited. A recent case series of 16 patients with unresectable extracranial metastatic HPC showed partial tumor response in 11 patients (79\%) after administration of combination temozolomide and bevacizumab. Patients on this empirically designed regimen had a median progression free and overall survival of 9.7 and 24.3 months, respectively [26]. Because of the expression of PDGFR and VEGFR on HPC tumor cells agents which target these receptors or their ligands are an attractive treatment strategy. In this regard, the multi-targeted tyrosine kinase inhibitor pazopanib has been shown to have some clinical efficacy in patients with metastatic HPC [27]. Further consideration should be given to evaluating these agents in an adjuvant setting, particularly in patients considered high risk for recurrent disease.

Metastatic hemangiopericytoma with hepatic metastases remains a rare and challenging diagnosis. A management scheme for an individual patient should be based on the extent and distribution of liver lesions, symptom complex, status of the primary tumor, presence of extrahepatic metastases, and performance status. Several therapies have been shown to result in reasonably durable progression free and overall survival, even in the setting of diffuse disease. We submit that a multidisciplinary approach is critical to optimizing treatment and outcomes for these unique patients.

\section{References}

1. Stout AP, Murray MR. Hemangiopericytoma: a vascular tumor featuring
Zimmermann's pericytes. Annals of Surgery. 1942; 116: 26-33.

2. Koch M, Nielsen GP, Yoon SS. Malignant tumors of blood vessels: angiosarcomas, hemangioendotheliomas, and hemangioperictyomas. J Surg Oncol. 2008; 97: 321-329.

3. Park BJ, Kim YI, Hong YK, Jeun SS, Lee KS, Lee YS. Clinical analysis of intracranial hemangiopericytoma. J Korean Neurosurg Soc. 2013; 54: 309316.

4. Enzinger FM, Smith BH. Hemangiopericytoma. An analysis of 106 cases. Hum Pathol. 1976; 7: 61-82.

5. Mena H, Ribas JL, Pezeshkpour GH, Cowan DN, Parisi JE. Hemangiopericytoma of the central nervous system: a review of 94 cases. Hum Pathol. 1991; 22: 84-91.

6. Espat NJ, Lewis JJ, Leung D, Woodruff JM, Antonescu CR, Shia J, et al. Conventional hemangiopericytoma: modern analysis of outcome. Cancer. 2002; 15: 1746-1751.

7. Spitz FR, Bouvet M, Pisters PW, Pollock RE, Feig BW. Hemangiopericytoma: a 20-year single-institution experience. Ann Surg Oncol. 1998; 5: 350-355.

8. Soyuer S, Chang EL, Selek U, McCutcheon IE, Maor MH. Intracranial meningeal hemangiopericytoma: the role of radiotherapy: report of 29 cases and review of the literature. Cancer. 2004; 100: 1491-1497.

9. Guthrie BL, Ebersold MJ, Scheithauer BW, Shaw EG. Meningeal hemangiopericytoma: histopathological features, treatment, and long-term follow-up of 44 cases. Neurosurgery. 1989; 25: 514-522.

10. Lu L, Zhang LJ, Zhou CS, Lu GM. Rectal hemangiopericytoma in a 37-yearold woman: a case report and review of the literature. J Med Case Rep. 2011; 5: 352 .

11. Chiechi MV, Smirniotopoulos JG, Mena H. Intracranial hemangiopericytomas: MR and CT features. AJNR Am J Neuroradiol. 1996; 17: 1365-1371.

12. Aliberti C, Benea G, Kopf B, De Giorgi U. Hepatic metastases of hemangiopericytoma: contrast-enhanced MRI, contrast-enhanced ultrasonography and angiography findings. Cancer Imaging. 2006; 6: 56-59.

13. Han N, Kim H, Min SK, Paek SH, Park CK, Choi SH, et al. Meningeal Solitary Fibrous Tumors with Delayed Extracranial Metastasis. J PatholTransl Med. 2016:50: 113-121.

14. Schweizer L, Koelsche C, Sahm F, Piro RM, Capper D, Reuss DE, et al. Meningeal hemangiopericytoma and solitary fibrous tumors carry the NAB2STAT6 fusion and can be diagnosed by nuclear expression of STAT6 protein Acta Neuropath. 2013; 125: 651-658.

15. Trabelsi S, Mama N, Chourabi M, Mastouri MH, Ladib M, Popov S, et al. Meningeal Hemangiopericytomas and Meningomas: a Comparative Immunohistochemical and Genetic Study. Asian Pac J Cancer Prev. 2015; 16: 6871-6876.

16. Macagno N, Figarella-Branger D, Mokthari $K$, Metellus $P$, Jouvet $A$, Vasiljevic $A$, et al. Differential Diagnosis of Meningeal SFT-HPC and Meningioma: Which Immunohistochemical Markers Should Be Used? Am J Surg Pathol. 2016; 40: 270-278.

17. Chen LF, Yang Y, Yu XG, Gui QP, Xu BN, Zhou DB. Multimodal treatment and management strategies for intracranial hemangiopericytoma. J Clin Neurosci. 2015; 22: 718-725.

18. Rutkowski MJ, Jian BJ, Bloch O, Chen C, Sughrue ME, Tihan T, et al. Intracranial hemangiopericytoma: clinical experience and treatment considerations in a modern series of 40 adult patients. Cancer. 2012; 118: 1628-1636.

19. Grunenberger F, Bachellier P, Chenard MP, Massard G, Caraman PL. Hepatic and pulmonary metastases from a meningeal hemangiopericytoma and severe hypoglycemiadue to abnormal secretion of insulin-like growth factor: a case report. Cancer. 1999; 85: 2245-2248.

20. Davda R, Seddon BM. Mechanisms and management of non-islet cell tumourhypoglycaemia in gastrointestinal stromal tumour: case report and a review of published studies. ClinOncol (R Coll Radiol). 2007; 19: 265-268. 
21. Bodnar TW, Acevedo MJ, Pietropaolo M. Management of non-islet-cell tumo hypoglycemia: a clinical review. J Clin Endocrinol Metab. 2014; 99: 713-722.

22. Manatakis DK, Delis SG, Ptohis N, Korkolopoulou P, Dervenis C Multidisciplinary Approach to Hepatic Metastases of Intracranial Hemangiopericytoma: A Case Reportand Review of the Literature. Case Rep Oncol Med. 2015; 2015: 214306.

23. Iwamuro M, Nakamura S, Shiraha H, Kobayashi Y, Fukatsu H, Yamamoto K. A case of primary intracranial hemangiopericytoma with hepatic metastases: successful treatment with radiofrequency ablation and transcatheter arterial chemoembolization. Clin J Gastroenterol. 2009; 2: 30-35.

24. Adams J, Lodge JP, Parker D. Liver transplantation for metastatic hemangiopericytoma associated with hypoglycemia. Transplantation. 1999; 67: 488-489.
25. Urata K, Ikegami T, Nakazawa $Y$, Ohno $Y$, Kobayashi A, Mita A, et al. Living-Donor Liver Transplantation for Hepatic Metastasis From Meningeal Hemangiopericytoma: A Case Report. Transplant Proc. 2015; 47: 2274-2277.

26. Park MS, Patel SR, Ludwig JA, Trent JC, Conrad CA, Lazar AJ, et al. Activity of temozolomide and bevacizumab in the treatment of locally advanced, recurrent, and metastatic hemangiopericytoma and malignant solitary fibrous tumor. Cancer. 2011; 117: 4939-4947.

27. Lee SJ, Kim ST, Park SH, Choi YL, Park JB, Kim SJ, et al. Successful use of pazopanib for treatment of refractory metastatic hemangiopericytoma. Clin Sarcoma Res. 2014; 4: 13.
Ann Hematol Oncol - Volume 4 Issue 3 - 2017

ISSN : 2375-7965 | www.austinpublishinggroup.com

Dickson et al. (C) All rights are reserved
Citation: Hendrick L, Angel W, Besh S, O'Brien T, Goins N and Dickson P. Multidisciplinary Management of Metastatic Hemangiopericytoma Presenting with Hypoglycemia. Ann Hematol Oncol. 2017; 4(3): 1140. 